\title{
INCLUSÃO DE CRIANÇAS COM HIDROCEFALIA EM PRÁTICAS DE LETRAMENTO: ABORDAGEM NEUROLINGUÍSTICA
}

\author{
DIONEIA MOTTA MONTE-SERRAT \\ $(\text { UNAERP })^{1}$
}

\begin{abstract}
RESUMO: Os fundamentos teórico-metodológicos da Neurolinguística Discursiva (Coudry, [1986] 1988) e do Letramento (Tfouni, 2005) articulam-se, neste artigo, com o intuito de estudar marcas de subjetividade nas produções orais e escritas de crianças com lesão cerebral para promover a inclusão social destas. Dentre as lesões cerebrais, escolheu-se a hidrocefalia, afecção que decorre da quebra do equilíbrio do líquido cefalorraquidiano. Entre as sequelas apresentadas pela criança após o tratamento, a que mais preocupa é o retardo neuropsicomotor, uma vez que essa condição a coloca num quadro de marginalização social que é necessário mudar. Correlacionamos, neste artigo, teoria e conceitos com práticas metodológicas, a fim de observar o modo como as crianças hidrocéfalas dão corpo ao exercício discursivo da linguagem que a constitui como sujeito. Nosso objetivo central é o de desenvolver estratégias de avaliação adaptadas às dificuldades de funcionamento da linguagem nas crianças com essa afecção, estratégias essas que não sejam baseadas no desempenho de um sujeito idealizado, pois crianças com hidrocefalia não apresentam determinados recursos de produção e de interpretação de sentidos. Desse modo, pretendemos estabelecer um perfil teórico a respeito do uso da linguagem e seu efeito na constituição de sujeitos com lesão cerebral dando-lhes qualidade de vida.
\end{abstract}

Palavras-chave: Neurolinguística Discursiva; Letramento; Inclusão Social.

ABSTRACT: In this paper, the theoretical and methodological frameworks of Discursive Neurolinguistics (Coudry) and Literacy (Tfouni) are articulated with the purpose to study subjective marks in the oral and written productions of children with brain injury so as to promote their social inclusion. Among brain injuries, hydrocephalus, a disease that results from the imbalance of the cerebrospinal fluid Of the sequelae shown by patients after treatment, the one causing the most concern is neuropsychomotor retardation. Such condition places children in a situation of social marginalization that we intend to change by correlating theory and concepts to methodological practices in order to observe how children with hydrocephalus embody the discursive exercise of language as well as to observe its role in the subjects' use of language. Our final goal is to develop evaluation strategies adapted to the functioning difficulties of language in children with that disease. These strategies should not be based on the abstraction or performance of an idealized subject, since children with hydrocephalus do not show certain production or meaning interpretation resources. Thus, we intend to establish a theoretical profile of language use by children with brain injury and its effects in the subjects that will give them quality of life.

Keywords: Discursive Neurolinguistics. Literacy. Social Inclusion.

${ }^{1}$ Docente do Programa de Mestrado em Saúde e Educação, UNAERP. Pesquisadora colaboradora do IEL-UNICAMP. Contato: di_motta61@yahoo.com.br 


\section{INTRODUÇ̃̃O}

Conceitos advindos das áreas de Neurolinguística Discursiva (doravante $\mathrm{ND}$ ) e de Letramento estruturam este estudo, aliando o conhecimento teórico às práticas de linguagem verbal de crianças com hidrocefalia, propiciando uma visão mais ampla se comparada à da prática clínica tradicional, geralmente pautada pela abordagem quantitativa de dados, obtidos por meio de testes e baseada na noção de um sujeito idealizado, padronizado, impossível de corresponder à realidade. Neste artigo, seguimos outro rumo de investigação, abordando dados de linguagem que emergem no discurso ${ }^{2}$, destacando os processos de significação que se interpõem durante a enunciação da criança, diante da impossibilidade de dizer algo. Esse novo "caminho" constitui um modo particular de significação (Coudry, 2008, p. 7) que a criança hidrocefálica percorre ao falar sob determinadas condições de produção.

O escopo desta reflexão é o da inclusão social das crianças com hidrocefalia que apresentam dificuldades no uso efetivo da linguagem. Sem o domínio de práticas discursivas, dificilmente essas crianças alcançarão condições de inclusão social. Argumentamos que a base teórica proposta pelas pesquisas do Letramento (Tfouni, 1992, 2005; Monte-Serrat, 2013) permite, de fato, essa inclusão social, pois se afasta dos padrões pedagógicos que propõem parâmetros rígidos para $o$ que seria "certo" ou "errado" e se concentra na reflexão sobre o sujeito como autor na linguagem ${ }^{3}$, em narrativas ${ }^{4}$ orais de indivíduos alfabetizados ou não.

Consideramos, ainda, a abordagem neurolinguística na prática com a linguagem, com o outro e com o corpo, para que as crianças com lesão cerebral não sejam vistas como "incapazes" de "acertar" as respostas dos testes padronizados e que não sejam marginalizadas pela sociedade. Observamos, de acordo com Coudry ([1986]19885) em sua teoria da ND, que o fato de não serem alfabetizadas e de apresentarem disfunções na linguagem (França, 2011) acarretam dificuldades nos

${ }^{2}$ Discurso: prática regular de produção de texto oral ou escrito (Orlandi, 2008). Essa prática envolve, de um lado, a dimensão jurídica da língua e sua efetividade social (Edelman, 1980, p. 15) e, de outro, pode evidenciar o acontecimento (Pêcheux, 2002), ou seja, o deslocamento na estrutura discursiva que faz vislumbrar um sujeito resistente à formação ideológica dominante (Monte-Serrat e Tfouni, 2013).

${ }^{3}$ Conceito que abrange não só aspectos formais do sistema linguístico (níveis fonéticofonológico, sintático e semântico), como também aspectos pragmáticos e discursivos da linguagem, levando em conta que as funções mentais superiores são socialmente formadas e culturalmente transmitidas (Beilke, 2009).

${ }^{4}$ Utilizamos a teoria do letramento (Tfouni, 1992, 2005) como suporte teórico para avaliar narrativas em lugar de aplicar testes de cognição previamente preparados e baseados em um sujeito ideal. Nossas observações não se baseiam em achados abstratos, mas em achados da realidade vivida por sujeitos com hidrocefalia.

${ }^{5}$ Coudry, M. I. H. Diário de Narciso: discurso e afasia. Análise de interlocuções com afásicos. Tese de Doutorado em Linguística, Instituto de Estudos da Linguagem (IEL) da Universidade Estadual de Campinas, UNICAMP. 1986. A tese, publicada em forma de livro em 1988 pela Martins Fontes, é a obra fundante da Neurolinguística Discursiva (ND). 
processos de significação de seu discurso ${ }^{6}$ (Coudry, 2008): é com esse propósito que apresentamos uma teorização e proposta de intervenção.

\section{LESÃO CEREBRAL E AS CONSEQUÊNCIAS DE NÃO INCLUS̃̃o}

Escolhemos o tema da hidrocefalia ${ }^{7}$ em razão de acompanhamento de crianças e jovens com essa afecção tanto no CCAzinho, do Instituto de Estudos da Linguagem-UNICAMP, quanto no Departamento de Neurocirurgia Pediátrica e no HC-Criança, sendo estes dois últimos integrados à Faculdade de Medicina de Ribeirão Preto, FMRP-USP.

A hidrocefalia está associada à hipertensão intracraniana e a uma grande gama de doenças, além de se constituir como sequela de procedimentos cirúrgicos (Jucá et al. 2002, p. 1). Trata-se de uma afecção que decorre da quebra do equilíbrio entre produção/circulação e reabsorção do líquido cefalorraquidiano (Oliveira, 2011). A importância de nosso estudo se dá em razão dos seguintes achados: essa afecção apresenta índices preocupantes na população brasileira $(0,3$ $-2,5 / 1000$ ), segundo Oliveira (op. cit.), e estima-se que dentre as malformações congênitas, a hidrocefalia é a mais frequente, compreendendo aproximadamente $12 \%$ das malformações graves por ocasião do parto (Passini Jr. et al. 1998). Dentre os procedimentos realizados pela neurocirurgia pediátrica do Hospital das Clínicas da Faculdade de Medicina de Ribeirão Preto - USP, "o tratamento da hidrocefalia ocupa proporção de destaque, perfazendo, em conjunto com o tratamento da mielomeningocele ${ }^{8}$ e das craniossinostoses $9,60 \%$ do total" (Jucá et al., 2002, p. 1). Entre as sequelas apresentadas pelos pacientes após o tratamento da hidrocefalia, a que mais preocupa é o "retardo neuropsicomotor, fator limitante das potencialidades da criança e frequentemente causador de desajustes familiares e sociais" (Jucá et al., op. cit., p. 60; itálico da autora). Hoppe-Hirsch et al. (1998) afirmam que existe retardo de desenvolvimento em cerca de $60 \%$ dos pacientes com hidrocefalia submetidos à cirurgia. Machado e Oliveira afirmam que as infecções decorrentes do tratamento da hidrocefalia "representam o problema mais grave e mais temido, uma vez que colocam em risco a vida da criança e seu desenvolvimento intelectual futuro" (Machado e Oliveira, 2003, p. 137; itálico da autora).

Segundo relatório da Unicef (EBC, 2013), é preocupante o fato de a criança portadora de alterações no corpo e em suas funções ou estruturas ter menor acesso

${ }^{6} \mathrm{O}$ funcionamento discursivo consiste na prática da linguagem verbal (oral ou escrita) (Orlandi, 2008). Segundo Coudry (1988), uma abordagem dialógica possibilita o controle das condições de produção de sentido nas falas de sujeitos que apresentam disfunções de linguagem e passam por um processo de construção desta última.

${ }^{7}$ Este artigo é produto de pós-doutorado realizado no Instituto de Estudos da Linguagem, IELUNICAMP, sob a supervisão da Profa.Dra. Maria Irma Hadler Coudry, entre os anos de 2015 e 2016.

${ }^{8}$ Defeito congênito em que a espinha dorsal e o canal espinhal não se fecham antes do nascimento da criança, deixando de proteger a medula espinhal, os nervos e as meninges.

${ }^{9}$ Anomalia resultante da fusão prematura das suturas craniais, que impossibilita o cérebro de crescer normalmente. 
a recursos e serviços, ou seja, os seus direitos básicos de acesso à educação e à saúde ficam prejudicados. Esse relatório observa que as privações enfrentadas por essas crianças perpetuam sua condição de não inclusão social e impedem que políticas públicas adequadas sejam desenvolvidas.

\section{HIDROCEFALIA E AS ALTERAÇÕES BIOLÓGICAS QUE ACARRETA}

Não se pode ignorar o corpo que carrega a afecção; por esse motivo, passamos a expor alguns dados sobre a hidrocefalia. Afecção relacionada à hipertensão intracraniana (HIC), a hidrocefalia pode causar doenças neurológicas, dores de cabeça, perda visual, demência e até mesmo a morte do paciente. No cérebro há três componentes: parênquima cerebral, sangue e líquido cefalorraquiano (este com função metabólica, de acondicionamento do parênquima e de resistência a choque mecânico). Qualquer variação de volume em um desses três componentes provoca uma variação da pressão intracraniana (Mascarenhas, 2011). "Os valores fisiológicos da pressão intracraniana em humanos estão compreendidos entre 3 e $15 \mathrm{mmHg}^{10}$; qualquer alteração nos componentes do espaço intracraniano reflete-se nos valores da PIC ${ }^{11}$ " (Vilela et al., 2016). A pressão intracraniana, cuja monitoração assinala a elevação súbita, a manutenção em platô (60-80 mmHg) ou a queda abrupta, tem significado muito importante na evolução e prognóstico na lesão encefálica. Uma vez instalada a lesão neurológica, não há reversibilidade total desta, mas pode haver reversibilidade parcial com tratamento terapêutico específico de controle da pressão, com o auxílio do método não invasivo da PICMI $^{12}$ e com cirurgia para colocação de um shunt ${ }^{13}$.

Muitas lesões neurológicas se desenvolvem ao longo do tempo, começando de modo difuso (lesão primária) e, associadas a uma série de fatores no paciente, podem piorar as condições da pressão intracraniana, ocasionando lesões secundárias (Koji, 2011). Se essas lesões secundárias não forem monitoradas e tratadas adequadamente na tentativa de sua reversão, isso pode levar a uma sequela mais grave, com colapso funcional de alguma região, alterações metabólicas, neurotransmissores que alteram a estabilidade intracelular, ou até mesmo o óbito do indivíduo (Koji, op. cit.). Entre as graves sequelas decorrentes de afecção do sistema nervoso central, estão as alterações no desenvolvimento cognitivo da criança conforme assinalado pela Associação Espina Bífida e Hidrocefalia de Portugal (ASBIHP) ${ }^{14}$. Por esse motivo, é recomendável o monitoramento frequente da pressão intracraniana de crianças com hidrocefalia, preservando as

\footnotetext{
${ }^{10}$ Milímetros de mercúrio.

${ }^{11}$ Pressão Intracraniana.

${ }^{12}$ Ver nota 19, mais adiante, a esse respeito.

${ }^{13}$ Válvula implantada por meio de cirurgia, que tem como função permitir a drenagem do líquido cefalorraquidiano (LCR) existente dentro da caixa craniana. Essa válvula, acoplada a um tubo flexível de silicone, drena o excesso de líquido para a cavidade abdominal, reduzindo a pressão interna dos ventrículos cerebrais (AHME, 2013).

${ }^{14}$ Acesso ao site http://www.asbihp.pt/wp/ em 17 de junho de 2018.
} 
funções neurológicas remanescentes e dando a elas maiores chances de ter sua capacidade linguístico-cognitiva preservada.

O diagnóstico da hidrocefalia resulta da valorização do quadro clínico do paciente (cefaleia, vômitos e papiledema ${ }^{15}$ ); exames subsidiários auxiliam nesse diagnóstico, como, por exemplo, exames de Tomografia Computadorizada (TC) e Ressonância Nuclear Magnética (RNM) (Carlotti et al., 1998, p. 552). Há três possibilidades terapêuticas: o implante de válvula para auxiliar na derivação liquórica; a neuroendoscopia sem a necessidade de implante de válvula, ou o tratamento com medicamentos em casos específicos.

A introdução de drenagens valvuladas unidirecionais revolucionou $o$ tratamento da hidrocefalia, drenando o líquido em excesso dos ventrículos para cavidades do corpo e anulando, assim, as bases fisiopatológicas da hipertensão intracraniana (Jucá et al., 2002,). "A drenagem liquórica pode ser definitiva nos casos de hidrocefalia, através da instalação de um sistema de derivação, geralmente, ventriculoperitoneal" (Carlotti et al., 1998, p. 559).

Deve-se fazer o acompanhamento do paciente como um todo, verificando o nível Glasgow de consciência ${ }^{16}$ e monitorando sua pressão intracraniana, a fim de que se possa desenvolver tratamento específico para a lesão neurológica. A partir do parâmetro da pressão intracraniana é que serão tomadas medidas para o tratamento com medicações diuréticas, elevação da cabeceira da cama do paciente, tratamento medicamentoso, tratamento cirúrgico etc. (Koji, 2011). O monitoramento contínuo da pressão intracraniana previne não só a mortalidade infantil, mas também sérios danos nas funções neurológicas remanescentes, minimizando o impacto da doença no uso da linguagem e na vida futura da criança.

\section{REFLEXOS DAS ALTERAÇÕES DA PRESSÃO INTRACRANIANA NAS FUNÇÕES LINGUÍSTICO-COGNITIVAS ${ }^{17}$ DA CRIANÇA COM HIDROCEFALIA: UMA PERSPECTIVA DISCURSIVA}

A discussão neurocientífica assentada em parâmetros anátomo-orgânicos das consequências da hidrocefalia na criança é tema constante da literatura médica. Trabalhos têm sido desenvolvidos no sentido de avaliar: funções motoras como controle motor, força, marcha, postura e habilidade motora fina (Heterhington e Dennis, 1999); queda progressiva da cognição na criança com hidrocefalia (Whittle et al., 1985); melhora clínica na marcha, na incontinência e na cognição, após a implantação de shunt com o consequente controle da pressão intracraniana (Eide e Finset, 2007); melhora na cognição do paciente com a implantação de válvula e monitoramento da pressão intracraniana constante (Raftopoulos et al. 1994).

\footnotetext{
${ }^{15}$ Edema de papila por propagação da pressão intracraniana ao redor do nervo ótico.

${ }^{16}$ A Escala de Coma de Glasgow é uma escala padronizada utilizada na avaliação do nível de consciência em pacientes vítimas de lesão cerebral (Andrade et al., 2007). Se o valor apurado for inferior a 8, é indicada a medida invasiva da PIC, com a possibilidade de remoção de LCR para alívio da hipertensão e para análise (Carlotti et al. 1998, p. 556-557).

${ }^{17}$ A função cognitiva nesta pesquisa abarca aspectos cerebrais e mentais.
} 
Pretendemos acrescentar a essa discussão a perspectiva discursiva, a avaliação das dificuldades no uso da linguagem por essas crianças, pelo fato de a linguagem constituir uma atividade "que norteia as demais funções cognitivas" (Mármora, 2005, p. 1). Tem-se observado que, na hidrocefalia, embora a lesão cerebral se restrinja a áreas específicas, os mecanismos de linguagem se realizam sob processos mentais em uma hierarquia, afetando outras habilidades (Hydrocephalus Association, 2002; Dehaene, 2007). Essa reação em cadeia da lesão cerebral acarreta, para a criança, dificuldades em avaliar distâncias e direções; em organizar uma sequência de movimentos; e, no que diz respeito à sua fala, acarreta dificuldades na tarefa de selecionar informações relevantes de bases anteriores, afetando sua habilidade para interpretar significados (Oliveira e Pereira, s.d.). Essas crianças, em geral, fixam-se na interpretação literal da comunicação verbal, por terem prejudicadas suas habilidades de organização do campo visual-espacial, adaptação a situações novas ou inusitadas e de interpretação de sinais não verbais, como por exemplo, a linguagem corporal. As nuances entre tom, intensidade e ritmo das palavras no discurso podem passar despercebidos pela criança com hidrocefalia, o que é demonstrado por sua dificuldade em perceber a entonação ou os significados subentendidos. Esses fatores demonstram a necessidade de se desenvolver estratégia de trabalho sobre o contexto e o significado no uso da linguagem por essas crianças (Oliveira e Pereira, op. cit.), estratégia essa que encontramos nas teorias da Neurolinguística Discursiva (Coudry [1986] 1988) e do Letramento (Tfouni, 1992, 2005). A capacidade de aprendizagem das crianças por nós estudadas relaciona-se diretamente ao meio pelo qual um conteúdo lhe é apresentado (Coudry [1986] 1988), ou seja, o mediador, no processo de aprendizagem, deve observar mais o processo do que o produto da aprendizagem dessa criança (Nunes et al., 2011).

Em nossa abordagem interdisciplinar, o Letramento (Tfouni, 1992, 2005, 2008) fornece a base teórica para indagar se os sujeitos hidrocéfalos, em seu discurso, se apropriam da posição-sujeito autor, ou seja, se são criativos e se colocam como autores de seu próprio discurso, para motivar a criação da linguagem, engendrar a inquietação, o mistério que há por trás da leitura (Tfouni; Martha; Monte-Serrat, 2015). Para realizarmos as análises, nos debruçamos na produção discursiva realizada durante o acompanhamento longitudinal que realizamos, situação que nos permitiu trabalhar contexto e significado e, ao mesmo tempo, desenvolver estratégias e práticas de intervenção no processo de uso da linguagem por essas crianças, proporcionando-lhes meios para conter o deslize e a deriva de sentidos, permitindo a elas maior independência na relação com o outro, maior qualidade de vida e inclusão social. O diferencial que as teorias da Neurolinguística Discursiva e do Letramento trazem para este estudo é a possibilidade de estudar o discurso (oral ou escrito) despojado do raciocínio lógico imposto à linguagem pelas instituições (Tfouni, Carvalho; Monte-Serrat, 2017), o qual "equipa" o sujeito do conhecimento com a "verdade" (Certeau, 1994). Deixamos de lado os testes cognitivos comumente usados, que exigem utilização desse raciocínio lógico, - a que muitas crianças hidrocéfalas não têm acesso por exigirem habilidades de abstração -, para podermos incluir os 
não alfabetizados nas avaliações. Desse modo é possível observar a escrita e o sujeito em relação a ela (sujeito e contexto), pois o sujeito se constitui na enunciação (Elia, 2004).

Enquanto trabalhamos o conceito de autoria (Tfouni, 2008), buscamos, na ND (Coudry, [1986] 1988, 2008), observar como se dá o processo de constituição das significações no discurso das crianças com hidrocefalia. Por apresentarem lesões no sistema nervoso, os sujeitos hidrocéfalos prescindem de determinados recursos de produção de linguagem e de interpretação. A ND propõe a avaliação do uso da linguagem pela criança em processos de interação e com a intervenção do pesquisador, o que torna possível traçar um perfil teórico do funcionamento da linguagem e que permite à criança enfrentar novos desafios, em sua própria capacidade de aprender. Cremos que essa perspectiva "concentrada e aberta" (Deleuze e Guattari, 1995), sob a qual observamos aspectos científicos da hidrocefalia, alarga os limites de estudo desse tema e abre a oportunidade de ir além, propondo novas soluções que possam resultar em qualidade de vida e diminuir os problemas sociais decorrentes da marginalização da criança hidrocéfala.

A perspectiva sociocultural e humanizada trazida pela ND, desde os primeiros trabalhos de Coudry, propicia um olhar que vai além dos aspectos orgânicos/biológicos da hidrocefalia e fornece parâmetros para a compreensão das diferenças individuais. Com uma apreciação discursiva, ou seja, observando como se constituem os sentidos no funcionamento da linguagem da criança, é possível avaliar a melhor maneira de conduzi-la ao longo do processo de aquisição e uso da linguagem falada e escrita, maximizando suas potencialidades, combinando seus pontos fortes, necessidades e interesses (Rose e Meyer, 2002).

O que nos motiva nesse desafio é o fato de que o uso da linguagem é considerado tarefa neuropsicológica com função protetora do indivíduo em relação a patologias, uma vez que a linguagem interfere na constituição do sujeito que, por meio dela, pode alcançar também uma melhor qualidade de vida (Parente et al., 2009) ${ }^{18}$. Compreendemos a realidade do aprendizado da língua como processo de aquisição de conhecimento (Tfouni, 1992, 2005), e não como produto de um método. Desse modo, observamos a experiência de aprender a ler e escrever como tendo o potencial de provocar modificações na organização funcional do cérebro (Solé-Padullés et al., 2009). Pesquisadores observaram que o desenvolvimento de estratégias de ensino contribui na prevenção, na compensação ou no alívio das dificuldades de uso da linguagem (Bersh, 2008), modificando aspectos do funcionamento e da estrutura do cérebro (Solé-Padullés et al., op. cit.).

${ }^{18} \mathrm{O}$ estudo clínico das autoras afirma que, em sujeitos com lesão cerebral adquirida, há sobreposição do efeito da educação sobre o da lesão propriamente dita. 
CRIANÇASQUEAPRESENTAMDIFICULDADE DEAPRENDIZAGEM AVALIADAS EM UM ESPAÇO INTERDISCIPLINAR

Este estudo visa contribuir para diminuir a marginalização social das crianças com hidrocefalia, ao apontar questões teórico-metodológicas das áreas da ND (Coudry, [1986]/1988) e do Letramento (Tfouni, 1988, 1992, 2005). Uma dessas questões diz respeito aos testes que têm sido utilizados para avaliar os sujeitos. Essa interdisciplinaridade nos leva a questionar os pressupostos teóricometodológicos que baseiam os testes normalmente aplicados aos sujeitos com dificuldades de aprendizagem classificando-os como sujeitos com déficit.

Embora a ND se ocupasse inicialmente da afasia, suas bases teóricometodológicas aliadas à teoria do Letramento (Tfouni, 1992), trazem novos procedimentos de avaliação da linguagem em pacientes com hidrocefalia, adaptados às dificuldades de aprendizagem decorrentes dessa afecção. Esses novos procedimentos foram propostos por nós no atendimento longitudinal de uma criança com dificuldades na aquisição da linguagem oral e escrita, no Centro de Convivência em Linguagens (CCAzinho), no Instituto de Estudos da Linguagem (IEL/UNICAMP), coordenado pela Profa. Dra. Maria Irma Hadler Coudry.

$\mathrm{O}$ acompanhamento dessa criança baseia-se em perspectiva diversa daquela tradicional, da qual fazem parte os testes, seja para avaliar, seja para orientar a conduta terapêutica. A criança hidrocefálica a que nos referimos aprendeu a ler e a escrever ao longo de quatro anos (2012 a 2015) e passou a participar de um programa de inclusão em uma escola pública, o que constitui um direito de qualquer criança.

As possibilidades de novas propostas de avaliação se dão em razão de a ND se desenvolver em um espaço eminentemente interdisciplinar (França, 2011), envolvendo benefícios sociais e trocas de conhecimentos entre profissionais das áreas de linguística, psicologia, fonoaudiologia, ciências da computação, físicamédica, dentre outras ${ }^{19}$.

Essa colaboração interdisciplinar torna possível o aperfeiçoamento da investigação das condições neurológicas dos sujeitos com hidrocefalia e permite intervir de modo mais adequado nas dificuldades linguístico-cognitivas, a fim de que as crianças se apropriem de estratégias alternativas para enfrentar as

${ }^{19}$ No caso específico deste estudo, outros colaboradores se fizeram presentes, dentre os quais citamos o grupo de pesquisa coordenado pelo Prof. Dr. Sérgio Mascarenhas de Oliveira, IEA-USP, campus de São Carlos, em seu esforço de desenvolver o monitoramento da pressão intracraniana por método minimamente invasivo (PICMI) e não-invasivo (PICNI). Esse método pode ser comemorado como um grande avanço no que diz respeito à avaliação da pressão intracraniana em caso de lesões cerebrais, pois, além de não exigir trepanação - abertura de orifício no crânio por meio de broca neurocirúrgica - e inserção de um cateter através do crânio para medir a pressão intracraniana, traz as vantagens de ser mais acessível à população e de não expor o paciente a riscos de hematoma intracraniano, hemorragia ou infecção intracraniana. São, pelo menos, três os fatores relacionados ao método PICMI de aferição do LCR que interessam ao contexto de nosso estudo: (i) por se tratar de técnica não-invasiva de aferição da pressão intracraniana (PIC); (ii) por ter em vista sujeitos marginalizados por sua afecção e, por fim, (iii) por ser um método de monitoramento da pressão intracraniana acessível a pacientes de condição econômica menos favorecida. 
manifestações da doença e o isolamento linguístico e, assim, suas consequências emocionais, intelectuais e culturais.

\section{CONTRIBUIÇÕES DA TEORIA DO LETRAMENTO E DA NEURO- LINGUÍSTICA DISCURSIVA PARA PROVOCAR MODIFICAÇÕES NA ORGANIZAÇÃO FUNCIONAL DO CÉREBRO COM LESÃO}

A teoria do Letramento (Tfouni, 1992, 2005) estuda o uso da língua em um contexto sócio-histórico com foco no sujeito que dá corpo ao exercício discursivo da linguagem (Tfouni; Martha; Monte-Serrat, 2015), abrangendo alfabetizados e não alfabetizados. Sob essa perspectiva teórica, a avaliação das falas de crianças com hidrocefalia distancia-se de regras do "bem falar" e concentra-se em narrativas que permitem ao sujeito dar novos sentidos à sua fala, deslocando-se dos sentidos já estabelecidos (Tfouni, 2005). A perspectiva da teoria do Letramento possibilita a observação de algo que escapa à representação em um discurso (Quinet, 2002), permitindo vislumbrar o modo diferente como a criança hidrocéfala opera sobre a linguagem (Gaufey, 1998). No contexto deste artigo, colocamos em questão o conceito de autoria (Tfouni, 2008), como algo que pode permitir a observação do acontecimento discursivo (Pêcheux, 2002), ou seja, daquilo que leva o inconsciente a atravessar uma formação discursiva dominante (Pêcheux, 1988), constituindo um espaço de dissonância: o espaço do acontecimento discursivo (Pêcheux, op. cit.).

Do ponto de vista da ND, avaliar a linguagem dessas crianças significa considerar os "processos de descoberta e conhecimento das dificuldades que o sujeito apresenta, bem como [os] processos alternativos de significação de que lança mão para com elas lidar" (Coudry, 2002, p. 111). Nesse caso, os processos patológicos vivenciados pela criança são por nós tomados como situação particular relacionada aos processos normais de significação. Não os relacionamos a uma falha ou déficit (Coudry, op. cit.). Falhas e déficits são avaliados em testes padronizados para sujeitos ideais, sob a concepção normativa e culta da língua (Coudry, [1986] 1988; Tfouni, 2005). Nossa preferência pela oralidade nas observações se dá porque o processo oral tem formulações mais simples, ao contrário da escrita, que assume formas mais complexas no recurso às palavras e suas combinações. $\mathrm{O}$ fato de a teoria do Letramento privilegiar as narrativas nos leva a deixar de lado, nas investigações, os testes de cognição comumente utilizados, que exigem raciocínio abstrato, ao qual, regra geral, as crianças com hidrocefalia não têm acesso, conforme mencionado anteriormente.

O foco deste estudo está nos sujeitos pesquisados e, não, no conteúdo a ser abordado (Tfouni, 2005; Ferreiro e Teberosky, 1999). Questões aparentemente comportamentais da criança com hidrocefalia, se investigadas a fundo, são questões de dificuldades de aprendizagem. A hidrocefalia é uma afecção "invisível” que coloca a criança em estado de risco permanente. Para essa criança, não se trata de trabalhar duro ou de estudar mais: tudo é uma questão de aprender como trabalhar e estudar para que ela aprenda e apreenda conhecimentos e habilidades 
(Hydrocephalus Association, 2002.). Nossa aposta teórica, desde o início das observações, sempre foi a de que a criança, ao desenvolver sua narrativa com a participação e a intervenção do investigador, pode construir "uma imagem de continuidade, coerência e significação" (White, 1991, p. 15) da realidade em que vive, minimizando a dispersão de sentidos em seu discurso.

Buscamos compreender de que maneira o uso da linguagem por crianças com essa afecção pode ter um papel reorganizador. Segundo Coudry (2002), a avaliação da linguagem em contextos patológicos assenta-se no exercício de práticas que fazem sentido para o sujeito, por estarem ligadas a situações de uso social da linguagem. Esse procedimento de avaliação privilegia o fato de como o sujeito expressa sentidos e interpreta diálogos e leva em conta que o sentido não existe previamente, mas se constitui no contexto da enunciação (Coudry, 2002; Elia, 2004; Tfouni, 2005).

Inspirados pelo trabalho de Vygotsky ([1934] 2001) sobre o fato de que a relação entre palavra e significado se estabelece pela repetição da percepção simultânea de um som e de um objeto e de que o processo de atribuição de significado sofre transformações à medida que a criança se desenvolve, fizemos um estudo, supervisionado por Coudry, sobre as enunciações e sobre o discurso da criança com hidrocefalia, privilegiando os processos de construção de significação durante a interlocução. Consideramos o sujeito investigado "nas diversas vertentes de sua interação e, a partir daí, constru[ímos] o corpus de conhecimento do objeto de estudo" (Queiroz et al. 2007, p. 278).

\section{MÉTODO DE OBSERVAÇÃO PARTICIPANTE: AJUDANDO AS CRIANÇAS A CONSTRUÍREM O SENTIDO DO QUE DIZEM}

A perspectiva interdisciplinar de nossa investigação nos levou a optar pela adoção do método de observação participante pelos seguintes motivos: permite a interação com o sujeito observado, ajudando-o a construir o sentido daquilo que diz fornecendo-lhe pistas; apresenta características multimetodológicas (Queiroz et al. 2007). Esse método de investigação sai do âmbito de pesquisas quantitativas, cuja análise recai sobre a frequência positiva de repetição de eventos, e constituise ferramenta importante para construção do conhecimento em pesquisas que envolvem a área da saúde (Queiroz et al., op. cit.). Assim, podemos investigar aspectos linguístico-cognitivos simultaneamente; podemos avaliar não só a fala da criança, mas também seu corpo concernido na avaliação: a compreensão de um movimento de difícil execução distingue-se da execução e, para executá-lo, o corpo necessita compreender esse movimento (Bergson, [1939] 1999).

Nossa observação do quadro patológico da criança a inclui como sujeito na relação com a própria doença e com todos aqueles que a envolvem, relação essa mediada pela linguagem (Coudry, [1986] 1988; Tfouni, 1992, 2005). É na situação de dialogia que podemos observar como essas crianças falam e o que falam, produzindo processos de significação sob os desafios que sua condição lhes impõe (Coudry, 2002). 
Acompanhamos longitudinalmente, ao longo de dois anos, uma menina hidrocéfala, de 12 anos de idade ${ }^{20}$. A experiência de observação de crianças hidrocéfalas no Hospital das Clínicas da Faculdade de Medicina de Ribeirão Preto da USP, ao longo de quatro meses, nos permitiu inferir sobre pontos em comum com nossos achados decorrentes desse acompanhamento longitudinal. O diagnóstico médico identificando as áreas afetadas pela lesão foi a base para traçar a estratégia mais adequada de aprendizado da linguagem da criança. Com o diagnóstico em mãos, adaptamos o método de observação participativa (Queiroz et al. 2007) a um plano educativo individualizado (Hydrocephalus Association, 2002).

A importância desse plano individualizado foi a de delimitar as dificuldades da criança (que variam conforme as áreas cerebrais atingidas pela lesão), para estabelecer estratégias de superação dessas dificuldades e proporcionar aos pais e educadores um panorama das necessidades educacionais da criança. A linguagem de crianças com hidrocefalia tem características individuais porque as alterações das funções superiores decorrem não só da lesão nas áreas responsáveis por essas funções, mas também, pela desconexão provocada por lesões em áreas distantes e por influências socioculturais (Vieira et al. 2011, p. 595). Com esse plano individualizado pudemos tirar proveito dos pontos fortes das capacidades de compreensão e de aprendizagem da criança e minimizar os efeitos negativos que as dificuldades em outras capacidades provocariam.

Nossa teorização, portanto, produziu a forma de avaliação, distanciando-nos de testes padrão (Coudry, [1986] 1988; 2002). Nossa interação dialógica com a criança a ajudou a constituir a própria linguagem: "a incorporação do turno do interlocutor pela criança atua como um ponto de vista estruturante do próprio enunciado, da situação e da construção da realidade" (Coudry, 2002, p. 18). A criança teve oportunidade de organizar sua atenção para realização da ação, pois "a linguagem verbal mantém em um funcionamento ativo/seletivo a atenção para a realização de uma ação voluntária" (Mármora, 2005, p. 76).

Levamos em conta em nossa pesquisa os postulados do Brain Injury Research Center of Mount Sinai School of Medicine ${ }^{21}$, de que existe recuperação mais rápida nos primeiros seis meses após a lesão; essa recuperação continua rápida num período de dois anos, aproximadamente, e depois torna-se menos acelerada. Com a pesquisa teórica e com as sessões de acompanhamento longitudinal de sujeitos hidrocéfalos, refletimos sobre os processos linguístico-cognitivos subjacentes ao processo discursivo, a fim de compreender a dificuldade da criança hidrocéfala em relação ao aprendizado mais complexo e abstrato.

${ }^{20}$ A criança já vinha sendo alfabetizada no CCAzinho, por pesquisadores supervisionados por Coudry, no Laboratório de Neurolinguística do Instituto de Estudos da Linguagem, IEL-UNICAMP.

${ }^{21}$ Ver em http://icahn.mssm.edu/research/brain-injury/research/publications (Acesso em 28 de março de 2018). 


\section{IDENTIFICANDO O PROCESSO DE AUTORIA PARA OBSERVAR O SUJEITO QUE ENUNCIA}

Em razão do limite de espaço para esta publicação, nos deteremos agora sobre alguns importantes achados no acompanhamento de R., adolescente com má formação no corpo caloso e hidrocefalia. A partir de 2014, foram por nós realizadas sessões semanais de acompanhamento de leitura e escrita de R.. Embora R. já soubesse ler e escrever, tinha dificuldade em articular suas ideias para redigir um texto. Esse estudo implica a dificuldade de o indivíduo hidrocéfalo se expressar, levando-a a repetir o que ouve dos outros. A observação assistida com intuito de fazê-lo expressar suas próprias ideias e sentimentos (o que reflete autoria, uma vez que o sujeito tem algo a dizer de si mesmo enquanto enuncia) afeta positivamente sua qualidade de vida.

Inicialmente foi observado como se dava a percepção de R. na cadeia sintagmática da escrita. Para isso, trabalhamos a montagem de uma história baseada em texto lido na semana anterior; tivemos de relembrar os detalhes da história e R. tinha a tarefa de colocá-los em ordem cronológica. Paralelamente a essa atividade, foi feito um trabalho com caderno de caligrafia com tarefas para que R. pudesse treinar as letras cursivas. No início, ela teve um pouco de dificuldade nos movimentos motores ao desenhar as letras, mas não na identificação destas. O acompanhamento semanal começava com o exercício de caligrafia. Depois disso, era proposta a tarefa de montar texto com começo, meio e fim com base em palavras previamente dadas. Ficamos inventando vários finais para a história, até

que R. decidia por um deles e o escrevia. Às vezes, essas atividades eram realizadas em mais de um encontro. Como a escrita depende de raciocínio abstrato e lógico (Tfouni; Carvalho; Monte-Serrat, 2017), houve ocasiões em que propusemos exercícios de memorização de algarismos em sequência - habilidade que sujeitos com hidrocefalia não têm e precisa ser por eles aprendida - utilizando jogos infantis (principalmente o Ludo). Nosso objetivo era interferir no funcionamento neurológico, considerando a neuroplasticidade cerebral, na expectativa de que R. fosse capaz de aprender uma sequência temporal, apesar de, potencialmente, a afecção impedi-la de perceber a temporalidade, impedindo-a de distinguir entre o que é ir para frente e o que é ir para trás (Hydrocephalus Association, 2002).

Considerando que o cérebro em funcionamento não deve ser tomado como um depósito de conhecimentos, mas que é capaz de transformar o velho em novo (Ferrando, 2007), tomamos a aquisição e uso da linguagem por crianças com regiões do cérebro lesionadas em decorrência da hidrocefalia como algo sujeito à plasticidade neuronal, que desencadeia reciclagem para novas aprendizagens com base na dominância e especialização de áreas do hemisfério esquerdo para a linguagem verbal, capaz de processar formas cada vez mais complexas e abstratas (Dehaene, 2007). No caso em análise, R. conseguiu apreender bem a mecânica lógico-temporal, isto é, que existe uma sequência numérica que deve ser obedecida, relacionada a uma sequência temporal de antes-depois, por meio do jogo de Ludo, mas às vezes confundia o sentido em que as peças do jogo deveriam ser deslocadas (no sentido para a frente e, não, para trás, voltando ao ponto de partida). Esse jogo, 
portanto, ajuda no aprendizado de que existe uma sequência a ser seguida, no sentido para a frente, que deve ser exercitada na escrita, na interpretação correta dos números (por exemplo, número inteiro como o 21 não pode ser lido como 12 , realçando para R. que existe diferença nessas leituras). A sequência para a direita da leitura correta dos números permite não confundir, por exemplo, "17" com "71", exercício que tem reflexos no uso da linguagem, uma vez que a estruturação de sentenças segue o raciocínio lógico (Monte-Serrat e Belgacem, 2017; Whorf, 1942). "A lógica tem o papel de determinar as leis segundo as quais um sinal dará origem a outro sinal ou determinar o modo como um pensamento determinará outro pensamento" (Monte-Serrat e Belgacem, 2017, p. 23).

Anossa observação participativa nessas atividades minimizava a possibilidade de erros e a frustração, encorajando R. em seus novos desafios. Sabe-se que o progresso de $\mathrm{R}$. decorreu também do convívio salutar com seus pais e irmã e do intenso incentivo deles. $\mathrm{O}$ fato de os familiares da criança participarem do acompanhamento terapêutico interfere positivamente no progresso do tratamento de R.. Essa participação de familiares dá às crianças hidrocéfalas mais segurança quanto ao modo de agir. Os familiares se utilizam de estratégias para ajudá-las, oferecendo-lhes melhor qualidade de vida e não se restringem apenas aos cuidados higiênicos, alimentares e medicamentosos, como foi sugerido por Mármora (2005).

Ressaltamos que a participação do pesquisador deve ter uma continuação no contexto familiar da criança com lesão cerebral, para que não se perca a oportunidade da janela de plasticidade cerebral, que se "encolhe" em idade próxima aos vinte anos. R. desenvolve e aperfeiçoa a capacidade de raciocínio, coerência nas ideias e desenvoltura na escrita. Isso revela que o trabalho com a escrita age de modo sincrônico na constituição do sujeito, conjugando-se na prática que envolve a significação. Conforme Monte-Serrat:

O acompanhamento linguístico permite modificações rítmicas, lexicais, sintáticas, a fim de que se coloque em ordem a cadeia significante na produção oral ou escrita dos sujeitos. A interação linguística bem sucedida atua na estruturação da subjetividade, sempre levando em consideração o fato de que o investimento na capacidade neuronal reorganiza as funções envolvidas no uso da linguagem, estimula o funcionamento discursivo, tem função protetora em relação a patologias (Monte-Serrat, 2015, s.p.).

Um planejamento adaptado ao contexto sóciohistórico de cada criança possibilita que ela se aproprie da linguagem em uma situação de interlocução (Coudry, [1986] 1988, 2002). Cenas enunciativas, que fazem parte do seu dia a dia, mobilizam processos de significação verbais e não verbais, estratégias que permitem à criança uma "projeção do que pode e consegue dizer, usando de fato a linguagem para isto" (Coudry, 2002, p. 123), permitindo que ela improvise o que dizer e se saia bem no jogo dialógico.

Com esses pressupostos de análise, foi possível a R. desenvolver o seguinte texto: 


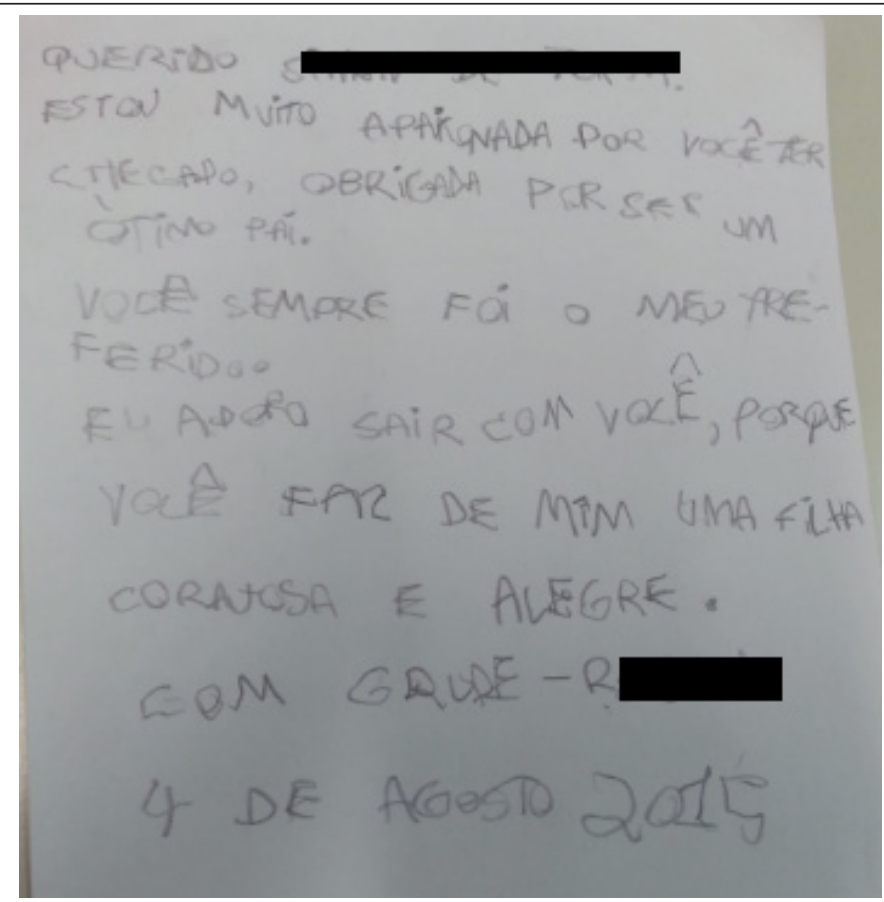

(Banco de Dados de Neurolinguística - BDN/ IEL, UNICAMP, 2015)

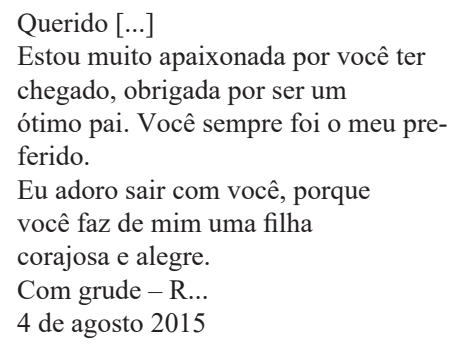

R. organiza e sistematiza suas ideias sobre a comemoração do dia dos pais. Sua escrita deixa de ser fragmentada e passa a relacionar-se a um contexto. R. consegue se expressar no mundo em que vive, controlando os sentidos e evitando a deriva, o que demonstra um processo de autoria. R. se coloca na origem do sentido daquilo que diz (Tfouni, 1992, 2005). Sua escrita com autoria promove visibilidade social e cria condições para sua inclusão e uma melhor qualidade de vida. Embora tenha uma disfunção cerebral, R. consegue colocar um valor particular naquilo que está enunciando (Foucault, ([1969] 2002; Monte-Serrat, 2017).

Essa conquista de R. nos leva a considerar que pessoas com afecção cerebral têm produção discursiva que expressa autoria e, se basearmos pesquisas e achados na metodologia qualitativa da Análise do Discurso (Pêcheux, 1988), deixamos 
de lado um sujeito idealizado capaz de erros e acertos (próprio da metodologia quantitativa) e nos baseamos em sujeitos que, em razão da plasticidade neuronal, podem desenvolver habilidades que os levem a elaborar produções escritas ou orais em que eles emergem como autores de seu discurso. Estas últimas são produções que se afastam de padrões e não deveriam ser sujeitadas às tradicionais avaliações cognitivas, as quais exigem a utilização de raciocínio abstrato, pois este último, segundo Oliveira e Pereira (s.d.) não está ao alcance de crianças hidrocéfalas.

As perspectivas da ND e do Letramento permitem a investigação de algo que escapa a uma avaliação quantitativa, possibilitando observar o modo diferente de como a criança com lesão cerebral opera sobre a linguagem. Permitem ao investigador valorizar os processos alternativos de significação (Coudry, [1986]1988) de que essa criança lança mão: são meios dos quais ela se utiliza para conter o deslize de sentidos.

\section{CONSIDERAÇÕES FINAIS}

Pesquisas interdisciplinares permitem uma melhor compreensão sobre o tema da hidrocefalia. Enquanto alguns pesquisadores e clínicos desenvolvem métodos para dar sobrevida às crianças hidrocefálicas, visamos dar a estas melhor qualidade de vida. As dificuldades enfrentadas por essas crianças são complexas e não estão exauridas nesta reflexão. Nosso estudo busca tornar possível a inclusão social dessa criança, por meio da linguagem que, como vimos, apresenta uma função protetora (Dehaene, 2007) do desenvolvimento cognitivo; potencializa a aprendizagem, o que pode ser ilustrado com o caso de R., que passa de um estado em que apenas repete o que dizem a ela para um estado em que se coloca como autora de seu discurso com criatividade e expressando seus sentimentos.

Pretendemos construir parcerias de modo a reunir esforços no sentido de que crianças com essas condições recebam, no âmbito educacional, o suporte e a ajuda de que realmente necessitam. Buscamos, ao final, não o estabelecimento do que seja "certo" ou do que seja "errado" na educação linguística da criança ou jovem com lesão cerebral. Nosso intuito é de chamar a atenção de educadores e de pesquisadores para a produção discursiva do sujeito com afecção cerebral, visando compreender quem são é sujeito em seu contexto particular relacionado ao corpo que carrega uma afecção. Esses sujeitos têm a capacidade de, mesmo com lesão cerebral, produzir significação em seu discurso e essa produção não deve ser avaliada em relação às falhas ou déficits. A atuação do pesquisador ou educador na cadeia discursiva do sujeito com afecção cerebral auxilia em sua constituição como sujeito (Elia, 2004), direcionando-o a constituir-se no simbólico, antecipando-lhe uma "normalidade" que lhe confere qualidade de vida e inserção social. 


\section{REFERÊNCIAS}

AHME, Associação de Hidrocefalia e Mielomeningocele de Ribeirão Preto. Criada em 2013 Disponível em https:/voluntariadobb.v2v.net/aggregators/526-associacao-de-hidrocefalia-emielomeningocele-de-ribeirao-preto-ahme Acesso em 10 de Junho de 2018.

ANDRADE, A; CARVALHO, R.; AMORIM, R.; PAIVA, W.; FIGUEIREDO, E.; TEIXEIRA, M. Coma e outros estados de consciência, In Rev Med, jul-set, 86(3), p. 123-131, São Paulo, 2007.

ASBIHP, Associação Spina Bifida e Hidrocefalia de Portugal. Disponível em http://www.asbihp. pt/using-joomla/extensions/modules/utility-modules/72-tratamento-da-hidrocefalia ou http:// www.asbihp.pt/wp/. Acesso em 10 de Junho de 2018.

BEILKE, H. Linguagem e memória na doença de Alzheimer: contribuições da neurolinguística para a avaliação de linguagem. Dissertação de Mestrado, pelo Programa de Pós-Graduação em Linguística do Instituto de Estudos da Linguagem da Universidade Estadual de Campinas (IELUNICAMP). Orientadora Profa. Dra. Rosana do Carmo Novaes Pinto. 2009. Disponível em http://cutter.unicamp.br/document/?code=000479309 ou http://www.bibliotecadigital.unicamp. br/. Acesso em 10de Junho de 2018.

BERGSON, H. (1939), Matéria e Memória - ensaio sobre a relação do corpo com o espírito. São Paulo: Martins Fontes, 1999.

BERSH, R. Introdução à Tecnologia Assistiva, CEDI, Centro Especializado em Desenvolvimento Infantil, Porto Alegre, 2008. Disponível em http://www.assistiva.com.br/Introducao_ Tecnologia_Assistiva.pdf. Acesso em 10 de Junho de 2018.

BRAIN INJURY RESEARCH CENTER OF MOUNT SINAI, Icahn School of Medicine at Mount Sinai. Disponível em: http://icahn.mssm.edu/research/brain-injury/research/publications. Acesso em 10 de Junho de 2018.

CARLOTTI, JR., C; COLLI, B.; DIAS, L. Hipertensão Intracraniana, Simpósio Medicina Intensiva: II Tópicos Selecionados. Capítulo V. In Revista Medicina, Ribeirão Preto 31: 552-562, out.-dez. 1998.

CERTEAU, M. A invenção do cotidiano: 1 Artes de Fazer, Petrópolis: Vozes, 1994.

COUDRY, M. I. H. Diário de Narciso: discurso e afasia. Análise de interlocuções com afásicos. Tese de Doutorado em Linguística, Instituto de Estudos da Linguagem (IEL) da Universidade Estadual de Campinas, UNICAMP, 1986.

COUDRY, M. I. H. Diário de Narciso: discurso e afasia. São Paulo: Martins Fontes, 1988.

COUDRY, M. I. H. Linguagem e Afasia: uma abordagem discursiva da neurolinguística, In Caderno de Estudos Linguísticos, (42): 99-129, Jan-Jun, IEL, UNICAMP, Campinas, 2002. Disponível em http://www.iel.unicamp.br/revista/index.php/cel/article/view/1602/1181. Acesso em 10 de Junho de 2018.

COUDRY, M. I. H. Neurolinguística Discursiva: afasia como tradução, In Estudos da Língua(gem), Vitória da Conquista, v. 6, n.2, p. 7-36, dezembro, 2008.

DEHAENE, S. Les neurones de la lecture, Paris: Odile Jacob, 2007. 
DELEUZE, G.; GUATTARI, F. Mil platôs, v. 1, Rio de Janeiro: Ed. 34 Letras, 1995.

EBC, Empresa Brasil de Comunicação. Relatório do Unicef aponta exclusão da criança com deficiência, 2013. Disponível em http://www.ebc.com.br/noticias/internacional/2013/06/relatorio-dounicef-aponta-exclusao-da-crianca-com-deficiencia. Acesso em 10 de Junho de 2018.

EIDE, F.; FINSET, A. Dementia and Geriatric Cognitive Disorders, In Karger Medical and Scientific, Publishers, 2007, 23, p. 47-54. Disponível em http://www.karger.com/Article/Pdf/96683. Acesso em 10 de Junho de 2018.

EDELMAN, B. La Practica Ideologica del Derecho, Madrid: Editorial Tecnos, 1980.

ELIA, L. O conceito de sujeito, Rio de Janeiro: Jorge Zahar, 2004.

FERRANDO, S. Compte rendu de l'ouvrage de Stanislas Dehaene "Les neurones de la lecture". Ed.Odile Jacob, 2007.

FERreiro, E.; TEBEROSKY, A. Psicogênese da língua escrita, Porto Alegre: Artes Médicas, 1999.

FOUCAULT, M. A arqueologia do saber. Trad. A.M. Sheridam Smith. Londres: Routledge, 2002.

FRANÇA, A. A Linguagem nas Neurociências, In Revista Linguística, UFRJ, v. 7, n. 2, dez. 2011. Disponível em http://www.letras.ufrj.br/poslinguistica/revistalinguistica/wp-content/ uploads/2013/06/Apresenta\%C3\%A7\%C3\%A3o-volume7-numero2.pdf. Acesso em 10 de Junho de 2018.

GAUFEY, G. El lazo especular. Un estudio traversero de la unidad imaginaria, trad Graciela Leguizamón, Argentina: Edelp SA, 1998.

Heterhington, R.; DENNIS, M. Motor Function Profile in Children With Early Onset Hydrocephalus, In Developmental Neuropsychology, 15(1), 25-51, Lawrence Erlbaun Associates, Inc., 1999. Disponível em http://www.tandfonline.com/doi/abs/10.1080/87565649 909540738\#preview. Acesso em 10 de Junho de 2018.

HOPPE-HIRSCH, E.; LAROUSSINIE, F.; BRUNET, L.; SAINTE-ROSE, C.; RENIER, D.; CINALLI, G.; ZERAH,M.; PIERRE-KAHN, A. Late outcome of the surgical treatment of hydrocephalus, In Child's Nervous System, 14: 97-99, Springer-Verlag, 1998.

HYDROCEPHALUS ASSOCIATION. A Teacher's Guide to Hydrocephalus, San Francisco: California, 2002.

JUCÁ, C.; LINS NETO, A; OLIVEIRA, R., MACHADO, H. Tratamento de Hidrocefalia com Derivação Ventriculo-Peritoneal: análise de 150 casos consecutivos no Hospital das Clínicas de Ribeirão Preto, In Acta Cirurgica Brasileira, vol. 17, supl. 3, São Paulo, 2002. Disponível em http://www.scielo.br/scielo.php?pid=S0102-86502002000900013\&script=sci_arttext. Acesso em 10 de Junho de 2018.

KOJI, T. Monitorização da PIC: indicações e técnicas, I Workshop em Pressão Intracraniana, Ribeirão Preto, SP, 07 de outubro de 2011.

MACHADO, H.; OLIVEIRA, R. Hidrocefalia Infantil, In AGUIAR, P.; PEREIRA, C.; ANDRADE FILHO, A. (orgs.). Emergência em Neurologia e Neurocirurgia, Revinter, 2003, p. 137-146. 
MÁRMORA, C.H. Uma hipótese funcional para a (a)praxia no curso da Doença de Alzheimer. Tese de Doutorado, Universidade Estadual de Campinas, Instituto de Estudos da Linguagem, Área de Concentração: Neurolinguística. Orientadora Maria Irma Hadler Coudry, 2005.

MASCARENHAS, S. Cenário geral sobre o novo método de monitorização da pressão intracraniana (PIC). I Workshop em Pressão Intracraniana, Ribeirão Preto, SP, 07 de outubro de 2011.

MONTE-SERRAT, D. O conceito de autoria na perspectiva da Educação Linguística: Neurolinguística, Linguagem e Sujeito. Comunicação oral no 2 Congresso Mackenzie Letras em Rede, 26 a 28 de Agosto de 2015. Disponível em https://www.researchgate.net/publication/280721237_ Neurolinguistica_linguagem_e_sujeito. Acesso em 10 de Junho de 2018.

MONTE-SERRAT, D. Letramento e discurso jurídico, Tese de Doutorado, apresentada à Faculdade de Filosofia, Ciências e Letras de Ribeirão Preto-USP. Área de concentração: Psicologia. Orientadora: Profa. Dra. Leda Verdiani Tfouni. Ribeirão Preto, 2013, 395p. Disponível em: http://www.teses.usp.br/teses/disponiveis/59/59137/tde-14032013-104350/ Acesso em 10 de Junho de 2018.

MONTE-SERRAT, D. O conceito de autoria na perspectiva da Educação Linguística - neurolinguística, linguagem e sujeito. Submetido para capítulo Inclusion in linguistic education: neurolinguistics, language and subject do livro Psycholinguistics and Cognition in Language Processing, 201701-27 (No prelo) Disponível em https:/scholar.google.com.br/scholar?q=Inclusion+in+linguis tic + education:+neurolinguistics, +language+and + subject + do + livro + Psycholinguistics + and $+\mathrm{Co}$ gnition + in + Language + Processing $\& h l=p t-B R \& a s \_s d t=0 \& a s \_v i s=1 \& o i=$ scholart

MONTE-SERRAT, D.; BELGACEM, F. Subject and Time Movement in the Virtual Reality, In International Journal of Research and Methodology in Social Science, V. 3, N.3, pp. 19-26, Jul-Sep 2017. Disponível em https://rive.google.com/file/d/1hm6uqtz64IdJdj44C0cUlj96HoyTYt_/view. Acesso em 10 de junho de 2018.

MONTE-SERRAT e TFOUNI, 2013NUNES, L.; BRAUN, P.; WALTER, C. Procedimentos e recursos de ensino para o aluno com deficiência: o que tem sido disseminado nos trabalhos do GT 15 da ANPED sobre estes temas?, In Revista Brasileira de Educação Especial, vo.1 17, p. 23-40, 2011. Disponível em http://www.scielo.br/scielo.php?pid=S1413-65382011000400004\&script=sci_ abstract\&tlng=pt. Acesso em 10 de Junho de 2018.

OLIVEIRA, I; PEREIRA, M. Orientação a professores sobre hidrocefalia, tradução e resumo de capítulo do livro A teacher's guide to hydrocephalus. Texto não publicado s.d.

OLIVEIRA, R. Avaliação de crianças portadoras de hidrocefalia e sistema de derivação ventricular, Disciplina de Neurocirurgia, Faculdade de Medicina de Ribeirão Preto, Universidade de São Paulo, I Workshop em Pressão Intracraniana, Ribeirão Preto, SP, 07 de outubro de 2011.

OLIVEIRA, R; MACHADO, H. Avaliação da velocidade do fluxo sanguíneo cerebral através da utilização do Doppler Transcraniano em crianças e adolescentes com hidrocefalia, In Acta Cirurgica Brasileira, vol. 15, suppl. 2, São Paulo, Brasil, 2003.

ORLANDI, E. Discurso e texto, Campinas: Pontes, 2008.

PARENTE, M.A.; SCHERER, L.; ZIMMERMANN, N.; FONSECA, R. Evidências do papel da escolaridade na organização cerebral, In Revista Neuropsicologia Latinoamericana, vol 1, $\mathrm{n}^{\circ}$

524 Cadernos de Estudos Linguísticos Campinas, v.60 n.2 p. 507-526 - mai./ago. 2018 
1, 2009, p. 72-80. Disponível em http://www.neuropsicolatina.org/index.php/ Neuropsicologia Latinoamericana/article/viewFile/11/9. Acesso em 18 de junho de 2018

PASSINI JÚNIOR, R.; NÓBREGA, S.; CECATTI, J.; BARINI, R.; SILVA, J. Diagnótico, Conduta Obstétrica e Resultados Perinatais em Fetos com Hidrocefalia, In Revista Brasileira de Ginecologia e Obstetrícia, v. 20, n. 7, Rio de Janeiro, agosto 1998.

PÊCHEUX, M. Semântica e Discurso: uma crítica à afirmação do óbvio, Campinas: Ed. Unicamp, 1988.

PÊCHEUX, M. O Discurso: estrutura ou acontecimento? 3ª Ed., Campinas, SP: Pontes, 2002.

QUEIROZ, D.; VALL, J.; SOUZA, A.; VIEIRA, N. Observação Participante na Pesquisa Qualitativa: conceitos e aplicações na área da saúde, In R. Enferm. UERJ, Rio de Janeiro, 2007, abril-junho, 15(2), p. 276-283.

QUINET, A. Um olhar a mais: ver e ser visto na psicanálise. Rio de Janeiro: Zahar Ed., 2002

RAFTOPOUlOS, C.; DEleVAl, J.; CHASKIS, C.; LEONARD, A.; CANTRAINE, F.; DESMYTTERE, F.; CLARYSSE, S.; BROTCHI, J. Cognitive Recovery in Idiopathic Normal Pressure Hydrocephalus: a Prospective Study, In Neurosurgery vol. 35, p.397-405, set. 1994. Disponível em http://journals.lww.com/neurosurgery/Abstract/1994/09000/Cognitive_ Recovery_in_Idiopathic_Normal_Pressure.6.aspx. Acesso em 10 de junho de 2018.

ROSE, D.; MEYER, A. Teaching Every Student in the Digital Age: Universal Design for Learning, ASCD, 2002. Disponível em http://www.cast.org/teachingeverystudent/ideas/tes/. Acesso em 10 de Junho de 2018.

SOLÉ-PADULLÉS, C.; BARTRÉS-FAZ, D.; JUNQUÉ, C.; VENDRELL, P.; RAMI, L.; CLEMENTE, I. C.; BOSH, B.; VILLAR, A.; BARGALLÓ, N.; JURADO, M.A.; BARRIOS, M.; MOLINUEVO, J.L. Brain structure and function related to cognitive reserve variables in normal aging, mild cognitive impairment and Alzheimer's disease. Neurobiology of aging, 30, 1114-1124, 2009.

TFOUNI, L. V. Letramento e analfabetismo. Tese de Livre-Docência, FFCLRP-USP, Ribeirão Preto, 1992.

TFOUNI, L. V. Letramento e alfabetização, São Paulo: Ed. Cortez, 2005.

TFOUNI, L. V. Autoria e contenção da deriva, In Múltiplas faces da autoria, TFOUNI, L.V. (org.), Ijuí: Ed. Unijuí, 2008.

TFOUNI, L.V.; MARTHA, D.; MONTE-SERRAT, D. Narrar para narrar-se: entre o livro e a sabedoria, a autoria, In Memorandum, 28, pp 132-144, 2015. Acesso em 10 de Junho de 2018. Disponível em http://www.fafich.ufmg.br/memorandum/wp-content/uploads/2015/05/ tfounimarthamonteserrat01.pdf

TFOUNI, L.V.; CARVALHO, A.; MONTE-SERRAT, D. A prática da oralidade como lugar de resistência, In: Antares-Letras e Humanidades, v. 9, n 17, p. 1-17, 2017. Disponível em http:// www.ucs.br/etc/revistas/index.php/antares/article/view/5075. Acesso em 10de Junho de 2018 
VIEIRA, A.C.; ROAZZI, A.; QUEIROGA, B.; ASFORA, R.; VALENÇA, M. Afasias e Áreas Cerebrais: Argumentos Prós e Contras à Perspectiva Localizacionista, In: Psicologia: Reflexão e Crítica, 24(3), 588-596, 2011. Disponível em http://cienciaparaeducacao.org/eng/publicacao/ vieira-a-c-c-roazzi-a-queiroga-b-asfora-r-valenca-m-m-afasias-e-areas-cerebrais-argumentospros-e-contras-a-perspectiva-localizacionista-psicologia-reflexao-e-critica-ufrgs/ Acesso em 10 de Junho de 2018.

VILELA, G. H.; CABELLA, B.; MASCARENHAS, S.; CZOSNYKA, M.; Smielewski, P.; DIAS, C.; CARDIM, D.; MASCARENHAS, Y.; WANG, C.; ANDRADE, R.; TANAKA, K.; LOPES, L.; COLLI, B. Validation of a New Minimally Invasive Intracranial Pressure Monitoring Method by Direct Comparison with an Invasive Technique. In: ANG, Beng-Ti (Ed.) Intracranial Pressure and Brain Monitoring. 15ed., 2016, p. 97-100.

VYGOTSKY, L. Pensamento e linguagem, [1934], versão para eBook , Ed. Ridendo Castigat Moraes., 2001.

WHITE, H. O valor da narratividade na representação da realidade, trad. José Luis Jobin, Niterói: Instituto de Letras da UFF, 1991.

WHITTLE, I; JOHNSTON, I; BESSER, M. Intracranial pressure changes in arrested hydrocephalus, In Journal of Neurosurgery, vol 62, p. 77-82, jan. 1985. Disponível em http://thejns.org/doi/ abs/10.3171/jns.1985.62.1.0077. Acesso em 10 de Junho de 2018 .

WHORF, B. ([1942]2017). Language, Mind and Reality, In Theosophist. India: Madras. January and April Issues, 1942. Retrieved on March 2, 2017, from http://web.stanford.edu/dept/SUL/library/ extra4/sloan/mousesite/Secondary/Whorfframe3.html. 